\title{
Evaluation of Risk Factors for Hepatotoxicity in Patients Receiving Antitubercular Four Drugs Regimen in Initial Two Months
}

\author{
Saifun Nahar Faiz ${ }^{1 *}$ \\ Nasreen Chowdhury ${ }^{2}$ \\ Md Aminul Haque Khan ${ }^{3}$ \\ Rukhsana Parvin ${ }^{4}$ \\ ${ }^{1}$ Department of Biochemistry \\ Southern Medical College \\ Chittagong, Bangladesh. \\ ${ }^{2}$ Department of Biochemistry \\ Chattagram Maa-O-Shishu Hospital Medical College \\ Chittagong, Bangladesh. \\ ${ }^{3}$ Department of Biochemistry \\ Enam Medical College, Savar, Dhaka, Bangladesh. \\ ${ }^{4}$ Department of Medicine \\ Enam Medical College, Savar, Dhaka, Bangladesh.
}

*Correspondence to:

\section{Dr. Saifun Nahar Faiz}

Assistant Professor

Department of Biochemistry

Southern Medical College, Chittagong, Bangladesh

Mobile: +8801818010081

E-mail:dr.snahar35cmc@yahoo.com

http://www.banglajol.info/index.php/CMOSHMCJ

\begin{abstract}
Background: Tuberculosis (TB) is a major public health problem in Bangladesh since long before. Standard first line drugs are isoniazid, rifampicin, pyrazinamide and ethambutol. Of these, isoniazid, rifampicin and pyrazinamide have been observed to have hepatotoxic potentials. Drug Induced Hepatotoxicity (DIH) is an important and commonly encountered adverse effect with anti-TB treatment. A higher risk of hepatotoxicity has been reported in Bangladeshi patients than in their western counterparts. The reasons for the higher rate of hepatotoxicity in Bangladeshi patients are unclear. Objectives: To know the possible risk factors for the development of drug induced hepatotoxicity and to see their association with hepatoxicity in patients receiving antitubercular treatment as per National Tuberculosis Control Programme. Materials and Methods: In this cross sectional prospective study, 100 freshly diagnosed pulmonary tuberculosis patients attending the Medicine Outpatient Department, admitted in Chittagong Medical College Hospital, DOTS center in the hospital were selected for the study. Results: In this study we found twenty percent patients (20\%) developed Antituberculosis Treatment (ATT) induced hepatotoxicity and most of them were in the age group of 50-65 years. Among the patients who developed hepatotoxicity (DIH) $27 \%$ patients were in BMI 18.5 group. The patients presenting with radiologically severe Pulmonary Tuberculosis (PTB) developed higher hepatotoxicity than patients with milder disease. The patients with history of high alcohol intake and with pre-treatment hypoalbuminemia were also found to have higher drug induced hepatotoxicity as compared to non-alcoholics and normal serum albumin level subjects. This study showed the evidence of ATT induced liver damage in twenty percent (20\%) patients. Among them $05 \%$ cases developed overt drug induced hepatotoxicity (DIH) and remaining $15 \%$ cases had asymptomatic elevation of serum ALT, AST and bilirubin levels. The remaining $80 \%$ cases did not show any significant change in their serum bilirubin and/or enzyme levels as compared to pre-treatment levels. Conclusion: Advanced age, high alcohol intake, radiologically severe disease before treatment and pretreatment hypoalbuminemia are predisposing factors for the development of ATT induced hepatotoxicity.
\end{abstract}

Key words: Drug induced hepatotoxicity; anti-tubercular treatment; DOTS.

\section{INTRODUCTION}

Tuberculosis (TB) is a socio-economic as well as highly contagious disaster that is occurring worldwide, especially in Asia. It is one of the most serious infectious diseases and a considerable public health problem due to its high risk of person-toperson transmission, morbidity, and mortality. World Health Organization (WHO) estimated that 9.4 million new cases of TB occurred worldwide in $2009,95 \%$ of them in developing countries of Asia (5.2 million), Africa, the Middle East and Latin America ${ }^{1}$. 
Drugs are an important cause of liver injury. Approximately $75 \%$ of the idiosyncratic drug reactions result in liver transplantation and death ${ }^{2,3}$. Drug induced hepatic injury is the most common reason cited for withdrawal of an approved drug. The manifestations of drug induced hepatotoxicity are highly variable, ranging from asymptomatic elevation of liver enzymes to fulminant hepatic failure ${ }^{4}$.

WHO has declared that tuberculosis is a global emergency. An effective control has been achieved by the widespread use of antitubercular drugs. But the antitubercular therapy (ATT) causes hepatotoxicity ${ }^{5-7}$. Early recognition of ATT induced hepatotxicity with immediate withdrawal of offending agent is very important to arrest its development. British Thoracic Society suggests that if there is a rise in Alanine Amino Transferase (ALT) and/or Aspertate Amino Transferase (AST) to greater than 3 times normal, or a rise in bilirubin, or if the patient shows clinical symptoms of hepatitis then drugs should be stopped and reintroduced sequentially when these parameters fall to previous levels ${ }^{8}$. Patients of tuberculosis usually belong to poor socioeconomic status and they cannot afford regular Liver Function Tests (LFTs). Close monitoring of the patient's physical condition can be done in such situations. Physician must be vigilant in identifying drug related liver injury because early detection can decrease the severity of hepatotoxicity if the drug is discontinued ${ }^{9}$.

The current recommended treatment regimens for tuberculosis involve drugs which are potentially hepatotoxic ${ }^{10}$. Certain genetic and environmental factors are attributed to coincide to produce sufficient quantity of toxic metabolites that then cause varied alterations in liver functions ${ }^{11}$.

The underlying mechanisms of ATT induced hepatotoxicity and the factors predisposing to its development are not clearly understood. The age, sex, poor nutritional status, chronic alcoholism, pre-existing liver disease, hypoalbuminaemia, advanced tuberculosis, acetaminophen, inappropriate use of drugs and acetylator status have all been incriminated as possible predisposing factors in earlier studies ${ }^{12}$. In this perspective, we designed this study to know the possible risk factors for the development of drug induced hepatotoxicity and the incidence of hepatic damage and overt hepatitis in patients receiving antitubercular treatment as per National Tuberculosis Control Programme (NTP) strategy.

\section{MATERIALS AND METHODS}

This cross sectional prospective study based on purposive sampling technique was conducted in department of Biochemistry of Chittagong Medical College, Chittagong during the period of July 2010 to January 2011. In this study, one hundred newly diagnosed pulmonary tuberculosis patients, both male and female, attending the medicine outpatient department, admitted in Chittagong Medical College Hospital and DOTS center in the hospital, were included. Patients who were diagnosed to have pulmonary tuberculosis with sputum smear positive for the first time were included.

\section{Exclusion criteria}

1. Patients with extra pulmonary tuberculosis.

2. Patients of pulmonary tuberculosis who were defaulters, treatment failure cases and multidrug resistance cases.

3. Patients with abnormal baseline liver function tests.

4. Patients with positive HbsAg, HIV, Anti HCV Ab, cirrhosis of liver, acute viral hepatitis and/or gastrointestinal, renal or cardiac diseases.

Detailed history of all subjects was taken and thorough clinical examination was done, including measurement of height and weight and calculation of BMI. History of high alcohol intake was noted. Severity of pulmonary tuberculosis (PTB) was assessed by chest radiography. Serum albumin level was also measured.

Before initiation of treatment, baseline investigations for alanine aminotransferase (ALT), aspartate aminotransferase (AST) and serum bilirubin were done. All these investigations were repeated after 2-month treatment with 4-drugs regimen (isoniazid, rifampicin, pyrazinamide and ethambutol). Patients with high levels of these parameters on repeat tests were categorized as having hepatotoxicity. Hepatotoxic patients were then evaluated for various factors.

Cut off values of the enzymes:

AST:

$\begin{array}{lllll}\text { Men } & \text { up to } & 41 \mathrm{U} / \mathrm{L} & \ldots \ldots \ldots & \text { At } 37^{\circ} \mathrm{c} \\ \text { Women } & \text { up to } & 32 \mathrm{U} / \mathrm{L} & \ldots \ldots \ldots & \text { At } 37^{\circ} \mathrm{c}\end{array}$

ALT:

Men up to $\quad 45 \mathrm{U} / \mathrm{L} \quad \ldots \ldots \ldots . . \quad$ At $37^{\circ} \mathrm{c}$ Women up to $\quad 32 \mathrm{U} / \mathrm{L} \quad \ldots \ldots \ldots$ At $37^{\circ} \mathrm{c}$

Serum bilirubin:

\section{$0.2-------1.2 \mathrm{mg} / \mathrm{dl}$}

\section{Statistical analysis}

Chi-square test was done to see the association of hepatotoxicity with different variables. $p$ value $<0.05$ was considered significant.

\section{RESULTS}

In the present study, we enrolled 100 patients who were diagnosed to have pulmonary tuberculosis for the first time. These patients were given DOTS therapy Four Fixed Dose Combination (4FDC)) as per National Tuberculosis Program (NTP) guidelines. All patients had normal liver function tests before the initiation of therapy. Liver function tests were repeated at $8^{\text {th }}$ week of the treatment to note the elevation in serum bilirubin and serum ALT and AST levels to find out the antituberculosis treatment induced hepatotoxicity. According to these investigation results we found that among 100 subjects 20 patients developed hepatotoxicity. 


\section{The time when pain started}

This study showed that pain was aggravated during work among the most respondents (46.9\%), and $14.3 \%$ respondents had continuous pain.

Table I : Biochemical profile of patients with hepatotoxicity $(n=20)$

\begin{tabular}{lccc} 
& $\begin{array}{c}\text { Mean ALT } \\
\text { U/L }\end{array}$ & $\begin{array}{c}\text { Mean AST } \\
\text { U/L }\end{array}$ & $\begin{array}{c}\text { Mean total bilirubin } \\
\text { mg/dL }\end{array}$ \\
Basal level & 32.5 & 30.0 & 0.7 \\
Peak level & 210.5 & 205.5 & 4.9 \\
After recovery & 85.7 & 63.4 & 1.1 \\
\hline
\end{tabular}

Table II: Association of age and BMI with hepatotoxicity $(n=100)$

\begin{tabular}{lcccc} 
Variables & Number & Percentage & $\chi^{2}$ value & p value \\
Age in years & & & & \\
$50-65(\mathrm{n}=50)$ & 17 & 34 & 11.4 & $<0.001$ \\
$15-49(\mathrm{n}=50)$ & 03 & 06 & & \\
BMI & & & & \\
$\geq 18.5(\mathrm{n}=30)$ & 08 & 27 & 1.0 & $>0.05$ \\
$<18.5(\mathrm{n}=70)$ & 12 & 17 & & \\
\hline
\end{tabular}

Table III: Association of pretreatment disease severity, alcohol consumption and serum albumin status of patients with hepatotoxicity $(\mathrm{n}=100)$

\begin{tabular}{|c|c|c|c|c|}
\hline Variables & Number & Percentage & $\chi^{2}$ value & $p$ value \\
\hline \multicolumn{5}{|c|}{ Severity of disease (PTB)* } \\
\hline Not severe $(n=65)$ & 04 & 06 & 22.2 & $<0.001$ \\
\hline Severe $(n=35)$ & 16 & 46 & & \\
\hline \multicolumn{5}{|c|}{ High alcohol intake } \\
\hline Yes $(n=26)$ & 16 & 62 & 37.89 & $<0.001$ \\
\hline No $(n=74)$ & 04 & 05 & & \\
\hline \multicolumn{5}{|c|}{ Serum albumin $(g / d L)$} \\
\hline$\geq 3.5(\mathrm{n}=44)$ & 02 & 05 & 11.71 & $<0.001$ \\
\hline$<3.5(\mathrm{n}=56)$ & 18 & 32 & & \\
\hline
\end{tabular}

* Severity of disease was assessed before treatment initiation by chest radiography

These results indicate that advancing age is an independent risk factor for drug induced hepatotoxicity. The patients in the age group of $\geq 50$ years were found 5.67 times higher to have hepatotoxicity as compared to the patients in the age group of $<50$ years $(\mathrm{p}<0.001)$.

In this study $27 \%$ patients in $\mathrm{BMI} \geq 18.5$ group developed Anti Tuberculosis Therapy (ATT )induced hepatotoxicity whereas in BMI $<18.5$ group $17 \%$ developed ATT induced hepatotoxicity $(\mathrm{p}>0.05)$.

The patients who presented with radiologically severe Pulmonary Tuberculosis (PTB) showed higher drug induced hepatotoxicity than patients presenting with radiologically milder disease $(\mathrm{p}<0.001)$. The patients with history of high alcohol intake were also found to have higher ATT induced hepatotoxicity as compared to non-alcoholics while receiving $\operatorname{ATT}(\mathrm{p}<0.001)$.
The patients presenting with pre-treatment hypoalbuminemia were found to have higher ATT induced liver damage than patients presenting with normal serum albumin levels $(\mathrm{p}<0.001)$.

In this study $20(20 \%)$ cases showed the evidence of ATT induced liver damage in the form of elevation of serum bilirubin, serum AST and ALT levels above normal. Among them $5(5 \%)$ cases developed overt Drug Induced Hepatotoxicity (DIH) as defined above and remaining 15 (15\%) cases had asymptomatic elevation of serum ALT, AST and bilirubin levels. The remaining $80(80 \%)$ cases did not show any significant change in their serum bilirubin and/or enzyme levels as compared to pre-treatment levels.

\section{DISCUSSION}

The development of drug-induced hepatitis during chemotherapy for tuberculosis is of great concern as it necessitates cessation or modification of treatment.Isoniazid, rifampicin and pyrazinamide have been observed to have hepatotoxic potential.

Several of drug induced liver damage have been described. Mechanisms of drug induced hepatotoxicity include idiosyncratic damage, dose dependent toxicity, induction of hepatic enzymes, drug induced acute hepatitis, allergic reactions. Specific patterns of hepatic damage include disruption of intracellular calcium homeostasis, cholestatic damage, interruption of transport pumps and loss of villous processes, reactions involving cytochrome p-450 system, activation of apoptotic pathways and programmed cell death and inhibition of mitochondrial function .

Fauzi et al13 have shown that older age group patients significantly more frequently developed hepatitis. Our study demonstrated a similar trend. In another study of Khoharo et al12, older age group was found affected more as compared to younger group. Regarding age, another study also showed increased incidence in old $(17.54 \%, 95 \%$ CI: 0.096 to 0.296 ) followed by mature and young groups. 14 Finding of our study is also strengthened by other studies. 15-17 It may be due to aging factor where decline of drug metabolism is a contributory factor. 15

In our study $17 \%$ of patients whose BMI were $<18.5$ and $27 \%$ of patients whose BMI were $\geq 18.5$ developed hepatotoxicity. But in the study of Khoharo et al12 where nutritional status of the patients was very poor $70 \%$ of patients having BMI below 18.5 developed hepatotoxicity. This difference between two studies may be due to small sample size in our study. Among the patients of who Khoharo et al12 who developed hepatotoxicity $75 \%$ showed hypoalbuminemia; this result is in agreement with our study. It may be one of the risk factors for the ATB-induced hepatotoxicity.8,9 High alcohol intake is a significant risk factor for development of drug-induced hepatitis. In the study of Khoharo et al12 alcoholism was not proved to be the predisposing factor for hepatotoxicity; but in our study the patients with history of high alcohol intake were found to have higher ATT induced hepatotoxicity as compared to non-alcoholics while receiving ATT. Study done by Pande et al18 revealed that high alcohol intake was recorded in $19.8 \%$ of the cases compared with $4.9 \%$ of the controls ( $<<0.001$ ). This is consistent with our study where $62 \%$ patients were 
alcoholic and the patients with history of high alcohol intake were found to have higher ATT induced hepatotoxicity as compared to non-alcoholics while receiving ATT.

In this study $20 \%$ cases showed the evidence of ATT-induced liver damage in the form of elevation of serum bilirubin, serum AST and ALT levels above normal. Study done by Rifat-uz-Zaman14 revealed that serum ALT, AST and total bilirubin levels were highly significantly $(p<0.001)$ increased after administration of anti-TB drugs. In the study by Shakya et al8, ATB was found to be associated with derangement of hepatic function, resulting in elevation of liver enzymes. Another study showed that there was 2 times increase in ALT observed in $38 \%$ of patients and more than 3 times elevation in 30\% patients within 12-60 days.16 Another study of hepatotoxicity in ATT patients attending the National Tuberculosis Center in Bhaktapur, Nepal showed that $15 \%$ patients developed $>51 \mathrm{IU} / \mathrm{L}$ increase in AST/ALT among 114 patients.

In a study of Pande et al18 the disease extent was also a significant risk factor for the development of hepatitis, with 12 of the 86 cases $(14.0 \%)$ having extensive disease but only 14 of the 406 controls $(3-5 \%)$. This result is also consistent with our study.

\section{LIMITATIONS OF THE STUDY}

The sample size was calculated excluding HIV, HBsAg and Anti-HCV antibody positive patients. So, it is not representing the whole population. Moreover, since the study was conducted only in urban health institutions in one city there might be a problem of representing the whole country.

\section{CONCLUSION}

From the findings in our study we can conclude that advancing age, history of high alcohol intake, radiologically severe form of PTB and pretreatment hypoalbuminemia are important risk factors except low BMI for development of ATT induced hepatotoxicity in Bangladeshi population. So early recognition of risk factors with close follow-up of patients receiving ATT and subjecting them to repeated liver function tests will significantly reduce morbidity and mortality and improve the compliance of the patients receiving ATT.

\section{ACKNOWLEDGEMENT}

The study was done at Chittagong Medical College, during the M.phil course of principal author.

\section{DISCLOSURE}

All the authors declared no competing interest.

\section{REFERENCES}

1. Raviglione MC, O’Brien RJ. Tuberculosis. In: Longo DL, Fauci AS, Kasper DL, Hauser SL, Jameson JL, Loscalzo J. Harrison's principles of internal medicine. $18^{\text {th }}$ edn. New York: Mc Graw-Hill Medical Publication Division. 2012; 1340-1359.

2. Nilesh Mehta, MD, Lisa Ozick, MD, Emmanuel Gbadehan, MD, 'Drug-Induced Hepatotoxicity'. Medscape reference, Drugs, Disease and procedure, April 26, 2010. Available at: http://emedicine.medscape.com/article/169814-overview. Accessed July 2014.

3. Crofton SJ, Norman H, Miller F. Clinical Tuberculosis. London: MACMILLAN Education Ltd. 1999;2:8-12.

4. National Guidelines and Operational Manual for Tuberculosis Control. Dhaka: Directorate General of Health Services. 2009: 4:12-15.

5. Mahmood K, Hossain A, Jairamani KL, Talib A, Abbasi BU, Salkeen S. Hepatotoxicity with anti-tuberculosis drugs: the risk factors. Pakistan Journal of Medical Sciences. 2007; 23(1): 56-59.

6. Nahar BL, Hossain AKMF, Islam MM, Saha DR. A comparative study on the adverse effects of two anti-tuberculosis drugs regimen in initial two-month treatment period. Bangladesh J Pharmacol. 2006; 1: 51-57.

7. Reid RT, Innes JA. Respiratory disease. In: Colledge NR, Walker BR, Ralston SH (eds). Davidson's principles and practice of medicine. Edinburgh: Churchill Livingstone Elsevier Ltd. 2010;21:641-730.

8. Shakya R, Rao BS, Shrestha B. Evaluations of risk factors for anti-tuberculosis drug-induced hepatotoxicity in Nepalese population. Kathmandu University Journal of Science, Engineering and Technology. 2006; 2(1): 1-8

9. Kishore PV, Palatan S, Pandol R, Mishra P, Prabhu M, Shankar PR. Drug induced hepatitis with anti-tubercular chemotherapy: challenges \& difficulties in treatment. Kathmandu University Medical Journal. 2007; 5(2): 256-260

10. Katzung BG. Basic and clinical pharmacology. Lange Medical Books /McGraw-Hill Medical Publishing Division. 2009;10:1409-1413.

11. Khadka J, Malla P, Jha SS, Poudel SR. The study of drug induced hepatotoxicity in ATT patients attending in national tuberculosis centre in Baktapur. SAARC J. TUBER. LUNG DIS.HIV/AIDS. 2009; 6(2): 17-21.

12. Khoharo HK, Ansari S, Siddique AA, Quraishi F. Standard antituberculosis drug induced hepatotoxicity; do the risk factors matter? JLUMHS. 2010; 9(2): 84-87.

13. Fauzi ARM, Shah A, Rathor MY, Satwi S. Risk factors for anti-tuberculous drugs induced hepatitis: a prospective survey from a chest clinic in a general hospital. Med J Malaysia 2004; 59(1): 72-77.

14. Rifat-uz-Zaman. Prevalence and risk factors of antitubercular drug-induced hepatitis in urban population of Bahawalpur district, Punjab, Pakistan. J App Pharm 2011; 2(03): 221-233.

15. Masako WADA. Anti-tuberculosis drug-induced hepatitis. Kekkaku 2005; 80(9): 607- 611

16. Tariq S, Khan TS, Malik S, Anwar SM, Rashid A. Frequency of anti-tuberculous therapy-induced hepatotoxicity in patients and their outcome. J Ayub Med Coll Abbott 2009; 21(4): 50-52.

17. Chang KC, Leung CC, Yew WW, Tam CM. Standard antituberculosis therapy and hepatotoxicity: do dosing schedule matters? Eur Resp J 2007; 29: 347-51.

18. Pande JN, Singh SPN, Khilnani GC, Khilnani S, Tandon RK. Risk factors for hepatotoxicity from antituberculosis drugs: a case control study. Thorax 1996; 51: 132-136. 